\title{
Desain dan Analisis Algoritma Pencarian Prediksi Hasil Penjumlahan Beberapa Urutan Berkala dengan Metode Eliminasi Gauss
}

\author{
Daniel Henry, Victor Hariadi, dan Rully Soelaiman \\ Departemen Teknik Informatika, Fakultas Teknologi Informasi, Institut Teknologi Sepuluh Nopember \\ (ITS) \\ e-mail: rully@is.its.ac.id
}

\begin{abstract}
Abstrak-Permasalahan dalam penelitian ini adalah permasalahan prediksi hasil penjumlahan beberapa urutan berkala. Dalam permasalahan ini, diberikan banyak urutan berkala $\mathbf{N}$ dimana panjang dari masing-masing urutan berkala berbeda satu dengan yang lainnya. Panjang dari urutan berkala dimulai dari $\mathrm{N}, \mathrm{N}-1, \mathrm{~N}-2$, hingga 1 . Diberikan nilai $\mathrm{f}(\mathbf{0}), \mathbf{f}(\mathbf{1}), \mathbf{f}(\mathbf{2})$, hingga $f\left(N^{2}-1\right)$, dimana $f(x)$ didefinisikan sebagai penjumlahan tiap elemen $\mathbf{N}$ buah urutan berkala. Selanjutnya ditanyakan nilai $f(x)$ dari nilai $x$ yang diberikan. Penelitian ini akan mengimplementasikan metode pencarian solusi sistem persamaan linear, yaitu metode eliminasi gauss. Implementasi dalam penelitian ini menggunakan bahasa pemrograman $\mathrm{C}++$. Hasil uji coba menunjukkan bahwa metode gauss eliminasi dapat menghasilkan jawaban permasalahan dengan benar, tetapi membutuhkan waktu yang sangat lama, yaitu dengan kompleksitas $\mathrm{O}\left(\mathrm{TN}^{6}+\mathrm{TN}^{3}\right)$. Perlu adanya optimasi dengan mengubah permasalahan ke dalam bentuk interpolasi trigonometri yang diselesaikan dengan metode interpolasi polinomial Lagrange dan perkalian polinomial yang diselesaikan dengan metode transformasi Fourier cepat.
\end{abstract}

Kata Kunci-Eliminasi Gauss, Sistem Persamaan Linear, Urutan Berkala.

\section{PENDAHULUAN}

$\mathrm{P}$ ENELITIAN ini terinspirasi dari banyaknya perusahaan yang melakukan prediksi siklus matahari, khususnya memprediksi jumlah bintik matahari per bulan, untuk menentukan umur dari satelit buatan yang berada pada orbit bumi rendah dikarenakan umur satelit buatan bergantung pada siklus matahari [1]. Peneliti tertarik untuk mengetahui lebih lanjut metode yang digunakan untuk memprediksi jumlah bintik matahari per bulan. Grafik jumlah bintik matahari per bulan mengikuti grafik hasil penjumlahan beberapa urutan berkala seperti yang terlihat pada Gambar 1 yang diambil dari situs NOAA [2].

Permasalahan prediksi hasil penjumlahan beberapa urutan berkala terdapat pada situs penilaian daring Sphere Online Judge (SPOJ) dengan kode soal PERIOD4 dengan judul Periodic function, trip 3 (easy) [1].

Pada permasalahan ini, diberikan banyak urutan berkala $\mathrm{N}$ dimana panjang dari masing-masing urutan berkala berbeda satu dengan yang lainnya. Panjang dari urutan berkala dimulai dari $\mathrm{N}, \mathrm{N}-1, \mathrm{~N}-2$, hingga 1 . Diberikan nilai $\mathrm{f}(0), \mathrm{f}(1), \mathrm{f}(2)$, hingga $f\left(\mathrm{~N}^{2}-1\right)$, dimana $\mathrm{f}(\mathrm{x})$ didefinisikan sebagai penjumlahan tiap elemen $\mathrm{N}$ buah urutan berkala. Untuk nilai $\mathrm{N}=2$ penjumlahan urutan berkala terdapat pada Tabel 1 dan untuk nilai $\mathrm{N}=3$ penjumlahan urutan berkala terdapat pada Tabel 2. Urutan $\mathrm{c}=\left(\mathrm{c}_{0}, \mathrm{c}_{0}, \mathrm{c}_{0}, \mathrm{c}_{0}, \mathrm{c}_{0}, \mathrm{c}_{0}, \ldots\right)$ merupakan urutan 1berkala yang berulang setiap satu bilangan, urutan $b=\left(b_{0}, b_{1}\right.$, $\left.\mathrm{b}_{0}, \mathrm{~b}_{1}, \mathrm{~b}_{0}, \mathrm{~b}_{1}, \ldots\right)$ merupakan urutan 2-berkala yang berulang setiap dua bilangan, dan urutan $\mathrm{a}=\left(\mathrm{a}_{0}, \mathrm{a}_{1}, \mathrm{a}_{2}, \mathrm{a}_{0}, \mathrm{a}_{1}, \mathrm{a}_{2}, \ldots\right)$ merupakan urutan 3-berkala yang berulang setiap tiga bilangan. Selanjutnya ditanyakan nilai $\mathrm{f}(\mathrm{x})$ dari nilai $\mathrm{x}$ yang diberikan. Semua hal di atas diulang sebanyak $\mathrm{T}$ kali.

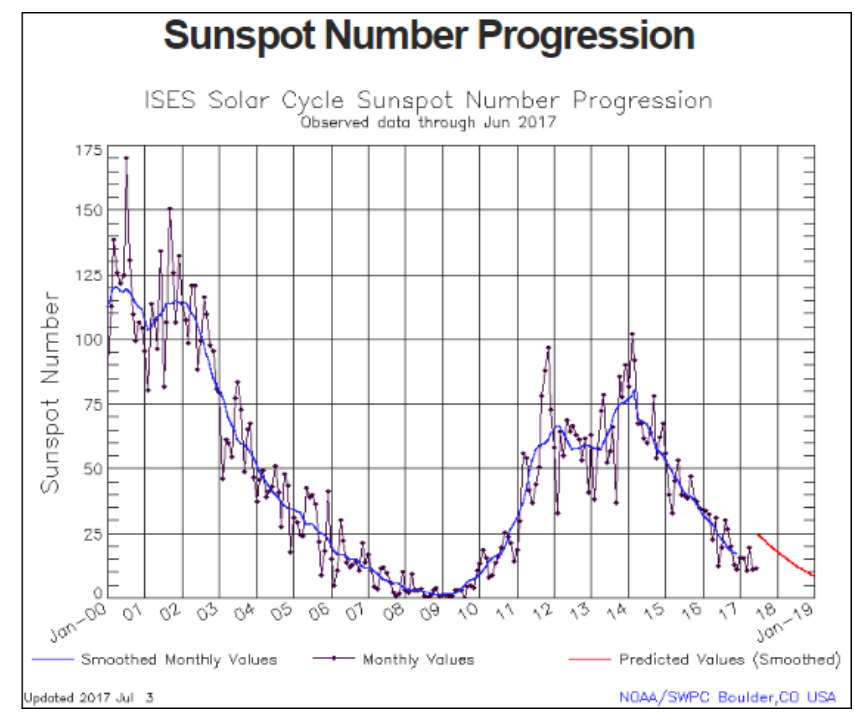

Gambar 1. Jumlah bintik matahari per bulan hingga Juni 2017

Tabel 1.

Definisi $\mathrm{f}(\mathrm{x})$ untuk $\mathrm{N}=2$ dengan 4 nilai $\mathrm{f}(\mathrm{x})$ diketahui

\begin{tabular}{lll}
\hline $\boldsymbol{x}$ & Definisi $\boldsymbol{f}$ & $\boldsymbol{f ( \boldsymbol { x } )}$ \\
\hline 0 & $b_{0}+c_{0}$ & $f(0)$ \\
1 & $b_{1}+c_{0}$ & $f(1)$ \\
2 & $b_{0}+c_{0}$ & $f(2)$ \\
3 & $b_{1}+c_{0}$ & $f(3)$ \\
4 & $b_{0}+c_{0}$ & $? ?$ \\
5 & $b_{1}+c_{0}$ & $? ?$ \\
6 & $b_{0}+c_{0}$ & $? ?$ \\
$\ldots$ & $\ldots$ & $\ldots$ \\
\hline \hline
\end{tabular}


Tabel 2.

Definisi $\mathrm{f}(\mathrm{x})$ untuk $\mathrm{N}=3$ dengan 9 nilai $\mathrm{f}(\mathrm{x})$ diketahui

\begin{tabular}{lll}
\hline \hline $\boldsymbol{x}$ & Definisi $\boldsymbol{f}$ & $\boldsymbol{f}(\boldsymbol{x})$ \\
\hline 0 & $a_{0}+b_{0}+c_{0}$ & $f(0)$ \\
1 & $a_{1}+b_{1}+c_{0}$ & $f(1)$ \\
2 & $a_{2}+b_{0}+c_{0}$ & $f(2)$ \\
3 & $a_{0}+b_{1}+c_{0}$ & $f(3)$ \\
4 & $a_{1}+b_{0}+c_{0}$ & $f(4)$ \\
5 & $a_{2}+b_{1}+c_{0}$ & $f(5)$ \\
6 & $a_{0}+b_{0}+c_{0}$ & $f(6)$ \\
7 & $a_{1}+b_{1}+c_{0}$ & $f(7)$ \\
8 & $a_{2}+b_{0}+c_{0}$ & $f(8)$ \\
9 & $a_{0}+b_{1}+c_{0}$ & $? ?$ \\
1 & $a_{1}+b_{0}+c_{0}$ & $? ?$ \\
0 & & \\
1 & $a_{2}+b_{1}+c_{0}$ & $? ?$ \\
1 & \\
1 & $a_{0}+b_{0}+c_{0}$ & $? ?$ \\
2 & $\ldots$ & $\ldots$ \\
$\ldots$ & $\ldots$ &
\end{tabular}

\section{TINJAUAN PUSTAKA}

\section{A. Urutan Berkala}

Urutan berkala (periodic sequence) [3] adalah suatu urutan $\mathrm{s}=\left(\mathrm{s}_{0}, \mathrm{~s}_{1}, \mathrm{~s}_{2}, \ldots\right)$ dimana $s_{i}=s_{i+N}$ untuk semua $i \geq 0$. Urutan $s$ juga bisa disebut sebagai urutan N-berkala, dimana $\mathrm{N}$ merupakan nilai periode dari urutan s. Sebagai contoh, urutan $\mathrm{U}=(2,3,4,2,3,4,2,3,4, \ldots)$ merupakan sebuah urutan 3berkala dan urutan $\mathrm{V}=(5,4,2,3,5,4,2,3,5,4,2,3, \ldots)$ merupakan sebuah urutan 4-berkala.

\section{B. Persamaan Linear}

Persamaan linear [4] dalam variabel $x$ dan $y$ didefinisikan sebagai sebuah garis lurus pada bidang datar $x y$ yang dapat direpresentasikan dengan persamaan (1) dimana $a_{1}, a_{2}$, dan $b$ merupakan konstanta real serta $a_{1}$ dan $a_{2}$ tidak bernilai 0 .

$$
\begin{aligned}
a_{1} x+a_{2} y & =b \\
a_{1} x_{1}+a_{2} x_{2}+\cdots+a_{n} x_{n} & =b
\end{aligned}
$$

Secara umum, persamaan linear dalam $n$ variabel $x_{1}, x_{2}, \ldots$, $x_{n}$ dapat ditulis ke dalam bentuk persamaan (2) dimana $a_{1}, a_{2}$, ..., $a_{n}$, dan $b$ merupakan konstanta real.

\section{Sistem Persamaan Linear}

Sistem persamaan linear [4] adalah kumpulan dari dua atau lebih persamaan linear dalam variabel $x_{1}, x_{2}, \ldots, x_{m}$. Sebuah urutan angka $s=\left(s_{1}, s_{2}, \ldots, s_{n}\right)$ disebut sebagai solusi dari suatu sistem persamaan linear jika $x_{1}=s_{1}, x_{2}=s_{2}, \ldots$, $x_{n}=s_{n}$ adalah solusi dari setiap persamaan linear dalam sistem.

$$
4 x_{1}-x_{2}+3 x_{a}=-1
$$

$$
3 x_{1}+x_{2}+9 x_{a}=-4
$$

Sebagai contoh, persamaan (3) dan (4) merupakan dua persamaan linear yang berada dalam suatu sistem persamaan linear, dimana memiliki solusi $x_{1}=1, x_{2}=2, x_{3}=-1$. Solusi ini dapat menyelesaikan persamaan (3) dan persamaan (4). Namun, $x_{1}=1, x_{2}=8, x_{a}=1$ bukan merupakan solusi sistem persamaan karena hanya menjadi solusi dari persamaan (3).

\section{Eliminasi Gauss}

Eliminasi gauss [5] adalah suatu algoritma yang digunakan untuk mencari solusi dari suatu sistem persamaan linear. Sistem persamaan linear (5) diubah ke dalam bentuk perkalian matriks, sehingga berubah bentuk menjadi persamaan (6).

$$
\begin{aligned}
& a_{11} x_{1}+a_{12} x_{2}+a_{12} x_{2}+\cdots+a_{1 n} x_{n}=b_{1} \\
& a_{21} x_{1}+a_{22} x_{2}+a_{2 a} x_{2}+\cdots+a_{2 n} x_{n}=b_{2} \\
& a_{n 1} x_{1}+a_{n 2} x_{2}+a_{n a} x_{a}+\cdots+a_{n n} x_{n}=b_{n} \\
& \begin{array}{r}
{\left[\begin{array}{ccccc}
a_{11} & a_{12} & a_{12} & \ldots & a_{1 n} \\
a_{21} & a_{22} & a_{22} & \ldots & a_{2 n} \\
\vdots & \vdots & \vdots & \ddots & \vdots \\
\vdots & \vdots & \vdots & \vdots & \vdots \\
a_{n 1} & a_{n 2} & a_{n 2} & \ldots & a_{n n}
\end{array}\right]} \\
A \\
A
\end{array}
\end{aligned}
$$

Dalam proses eliminasi gauss, matriks $A$ dilakukan operasi perkalian, penjumlahan, pengurangan, dan/atau pembagian baris matriks hingga terbentuk matriks $A^{s}$ pada persamaan (7).

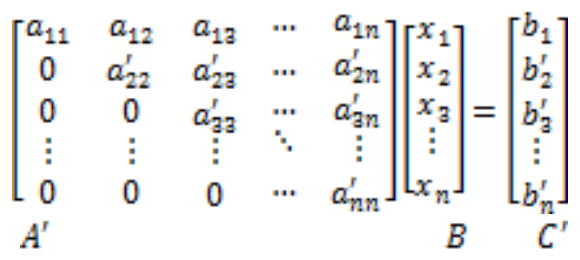

Selanjutnya, dilakukan proses back substitution agar mendapatkan solusi dari sistem persamaan linear. Gambar 2 menunjukkan proses eliminasi gauss dari awal sampai proses back substitution.

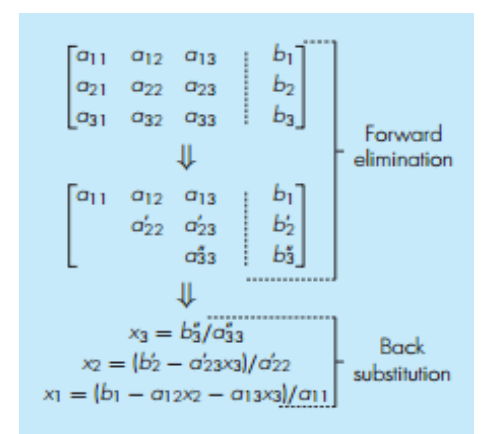

Gambar 2. Ilustrasi singkat proses eliminasi gauss 
Kompleksitas algoritma eliminasi gauss adalah $O\left(n^{\mathrm{a}}\right)$ dengan $n$ adalah banyaknya variabel pada satu persamaan linear pada sistem persamaan linear. Kompleksitas dari proses back substitution yaitu $O\left(n^{2}\right)$ dengan $n$ adalah banyaknya variabel. Total kompleksitas dari keseluruhan proses eliminasi gauss adalah $O\left(n^{\mathrm{a}}\right)$.

\section{STRATEGI PENYELESAIAN}

Untuk nilai $N=2$, definisi $f$ yang tertera pada Tabel 1 dapat diubah ke dalam bentuk sistem persamaan linear pada Tabel 3 dengan memasukkan semua variabel pada semua urutan berkala yang tersedia. Dalan kasus $N=2$, banyak urutan berkala adalah dua buah urutan, yaitu urutan 2-berkala berisi 2 variabel dan urutan 1-berkala berisi 1 variabel dengan total jumlah variabel adalah 3 variabel. Jumlah persamaan linear yang digunakan hanya 3 persamaan pertama dari 4 persamaan linear yang ada karena mengikuti total jumlah variabel yang digunakan.

Tabel 3.

Persamaan linear awal untuk $\mathrm{N}=2$

\begin{tabular}{ll}
\hline $\boldsymbol{x}$ & Persamaan Linear $\boldsymbol{f}(\boldsymbol{x})$ \\
\hline 0 & $1 b_{0}+0 b_{1}+1 c_{0}=5$ \\
1 & $0 b_{0}+1 b_{1}+1 c_{0}=7$ \\
2 & $1 b_{0}+0 b_{1}+1 c_{0}=5$
\end{tabular}

Untuk nilai $N=3$, definisi $f$ yang tertera pada Tabel 2 dapat diubah ke dalam bentuk sistem persamaan linear pada Tabel 4 dengan memasukkan semua variabel pada semua urutan berkala yang tersedia. Dalan kasus $N=3$, banyak urutan berkala adalah tiga buah urutan, yaitu urutan 3-berkala berisi 3 variabel, urutan 2-berkala berisi 2 variabel, dan urutan 1-berkala berisi 1 variabel dengan total jumlah variabel adalah 6 variabel. Jumlah persamaan linear yang digunakan hanya 6 persamaan pertama dari 9 persamaan linear yang ada karena mengikuti total jumlah variabel yang digunakan.

Tabel 4.

Persamaan linear awal untuk $\mathrm{N}=3$

\begin{tabular}{ll}
\hline \hline $\boldsymbol{x}$ & Persamaan Linear $\boldsymbol{f}(\boldsymbol{x})$ \\
\hline 0 & $1 c_{0}+0 c_{1}+0 c_{2}+1 b_{0}+0 b_{1}+1 c_{0}=15$ \\
1 & $0 c_{0}+1 c_{1}+0 c_{2}+0 b_{0}+1 b_{1}+1 c_{0}=3$ \\
2 & $0 c_{0}+0 c_{1}+1 c_{2}+1 b_{0}+0 b_{1}+1 c_{0}=17$ \\
3 & $1 c_{0}+0 c_{1}+0 c_{2}+0 b_{0}+1 b_{1}+1 c_{0}=2$ \\
4 & $0 c_{0}+1 c_{1}+0 c_{2}+1 b_{0}+0 b_{1}+1 c_{0}=16$ \\
5 & $0 c_{0}+0 c_{1}+1 c_{2}+0 b_{0}+1 b_{1}+1 c_{0}=4$
\end{tabular}

Banyak variabel dapat dikurangi dengan cara menjumlahkan variabel pada $q$-urutan berkala dengan variabel pada $q r$-urutan berkala sehingga menghasilkan $q r$-urutan berkala baru, dimana $q$ merupakan bilangan bulat positif dan $r$ merupakan bilangan bulat lebih besar dari 1 .

Tabel 5 menunjukkan banyak variabel awal yang dibutuhkan oleh setiap nilai $N$ pada selang $1 \leq N \leq 14$.
Tabel 5.

Banyak variabel awal setiap nilai $\mathrm{N}$

\begin{tabular}{cll}
\hline \hline $\begin{array}{l}\text { Banyak } \\
\text { Urutan } \\
\text { Berkala }\end{array}$ & & $\begin{array}{l}\text { Banyak } \\
\text { Variabel } \\
\text { Awal }\end{array}$ \\
Awal $(\boldsymbol{N})$ & & \\
\hline 1 & 1 & 1 \\
2 & $2+1$ & 3 \\
3 & $3+2+1$ & 6 \\
4 & $4+3+2+1$ & 10 \\
5 & $5+4+3+2+1$ & 15 \\
6 & $6+5+4+3+2+1$ & 21 \\
7 & $7+6+5+4+3+2+1$ & 28 \\
8 & $8+7+6+5+4+3+2+1$ & 36 \\
9 & $9+8+7+6+5+4+3+2+1$ & 45 \\
10 & $10+9+8+7+6+5+4+3+2+1$ & 55 \\
11 & $11+10+9+8+7+6+5+4+3+2+1$ & 66 \\
12 & $12+11+10+9+8+7+6+5+4+3+2+1$ & 78 \\
13 & $13+12+11+10+9+8+7+6+5+4+3+2+1$ & 91 \\
14 & $14+13+12+11+10+9+8+7+6+5+4+3+2+1$ & 105 \\
& & \\
\hline
\end{tabular}

Tabel 6 menunjukkan banyak variabel akhir yang dibutuhkan oleh setiap nilai $N$ pada selang $1 \leq N \leq 14$.

Tabel 6.

Banyak variabel akhir setiap nilai $\mathrm{N}$

\begin{tabular}{|c|c|c|c|}
\hline $\begin{array}{l}\text { Banyak } \\
\text { Urutan } \\
\text { Berkala } \\
\text { Awal } \\
(\boldsymbol{N})\end{array}$ & & $\begin{array}{l}\text { Banyak } \\
\text { Urutan } \\
\text { Berkala } \\
\text { Akhir } \\
(\boldsymbol{K}) \\
\end{array}$ & $\begin{array}{l}\text { Banyak } \\
\text { Variabel } \\
\text { Akhir } \\
(\boldsymbol{W})\end{array}$ \\
\hline 1 & 1 & 1 & 1 \\
\hline 2 & 2 & 1 & 2 \\
\hline 3 & $3+2$ & 2 & 5 \\
\hline 4 & $4+3$ & 2 & 7 \\
\hline 5 & $5+4+3$ & 3 & 12 \\
\hline 6 & $6+5+4$ & 3 & 15 \\
\hline 7 & $7+6+5+4$ & 4 & 22 \\
\hline 8 & $8+7+6+5$ & 4 & 26 \\
\hline 9 & $9+8+7+6+5$ & 5 & 35 \\
\hline 10 & $10+9+8+7+6$ & 5 & 40 \\
\hline 11 & $11+10+9+8+7+6$ & 6 & 51 \\
\hline 12 & $12+11+10+9+8+7$ & 6 & 57 \\
\hline 13 & $13+12+11+10+9+8+7$ & 7 & 70 \\
\hline 14 & $\begin{array}{l}14+13+12+11+10+9+ \\
8\end{array}$ & 7 & 77 \\
\hline
\end{tabular}

Sehingga, persamaan linear akhir untuk $\mathrm{N}=2$ tertera pada Tabel 7 dan persamaan linear akhir untuk $\mathrm{N}=3$ tertera pada Tabel 8. Sistem persamaan linear selanjutnya diselesaikan dengan eliminasi gauss untuk mendapatkan nilai yang ada pada masing-masing urutan berkala. Selanjutnya, nilai $f(x)$ dapat dicari dengan menggunakan nilai-nilai yang ada dalam urutan berkala. Kompleksitas total untuk menyelesaikan permasalahan yaitu $\mathrm{O}\left(\mathrm{TN}^{6}+\mathrm{TN}^{3}\right)$ dimana $\mathrm{T}$ menandakan banyak sub-kasus uji dan $\mathrm{N}$ merupakan banyak urutan berkala awal.

Tabel 7

Persamaan linear akhir untuk $\mathrm{N}=2$

\begin{tabular}{ll}
\hline \hline $\boldsymbol{x}$ & Persamaan Linear $\boldsymbol{f}(\boldsymbol{x})$ \\
\hline 0 & $1 b_{0}^{y}+0 b_{1}^{y}=5$ \\
1 & $0 b_{0}^{y}+1 b_{1}^{y}=7$ \\
\hline \hline
\end{tabular}


Tabel 8.

Persamaan linear akhir untuk $\mathrm{N}=3$

\begin{tabular}{|c|c|}
\hline $\mathrm{A}$ & Persamaan Linear $\boldsymbol{f}(\boldsymbol{x})$ \\
\hline 0 & $1 c_{0}+0 c_{1}+0 c_{2}+1 b_{0}^{s}+0 b_{1}^{s}=15$ \\
\hline 1 & $0 c_{0}+1 c_{1}+0 c_{2}+0 b_{0}^{v}+1 b_{1}^{v}=3$ \\
\hline 2 & $0 c_{0}+0 c_{1}+1 c_{2}+1 b_{0}^{b}+0 b_{1}^{b}=17$ \\
\hline 3 & $1 c_{0}+0 c_{1}+0 c_{2}+0 b_{0}^{s}+1 b_{1}^{s}=2$ \\
\hline 4 & $0 c_{0}+1 c_{1}+0 c_{2}+1 b_{0}^{j}+0 b_{1}^{j}=16$ \\
\hline
\end{tabular}

\section{UJI COBA DAN ANALISIS}

\section{A. Uji Coba Kebenaran}

Uji coba kebenaran dilakukan dengan membandingkan keluaran yang dihasilkan solusi berdasarkan masukan yang dibuat oleh data generator, dengan keluaran yang dibuat oleh data generator.

Tabel 9.

Percobaan perbandingan jawaban solusi dengan jawaban benar

\begin{tabular}{cccc}
\hline \hline $\begin{array}{l}\text { Uji } \\
\text { coba } \\
\text { ke- }\end{array}$ & $\begin{array}{l}\text { Total selisih angka } \\
\text { keluaran hasil solusi dan } \\
\text { keluaran benar }\end{array}$ & $\begin{array}{l}\text { Jumlah jawaban } f(x) \\
\text { sesuai per jumlah jawaban } \\
\text { total }\end{array}$ & $\begin{array}{l}\text { Akuras } \\
\text { i }\end{array}$ \\
\hline 1 & 0 & $61000 / 61000$ & $100 \%$ \\
2 & 0 & $71500 / 71500$ & $100 \%$ \\
3 & 0 & $6422 / 6422$ & $100 \%$ \\
4 & 0 & $17742 / 17742$ & $100 \%$ \\
5 & 0 & $26487 / 26487$ & $100 \%$ \\
6 & 0 & $32334 / 32334$ & $100 \%$ \\
7 & 0 & $37199 / 37199$ & $100 \%$ \\
8 & 0 & $44149 / 44149$ & $100 \%$ \\
9 & 0 & $49108 / 49108$ & $100 \%$ \\
10 & 0 & $56397 / 56397$ & $100 \%$ \\
11 & 0 & $61681 / 61681$ & $100 \%$ \\
12 & 0 & $64381 / 64381$ & $100 \%$ \\
13 & 0 & $71981 / 71981$ & $100 \%$ \\
14 & 0 & $1597 / 1597$ & $100 \%$ \\
15 & 0 & $5745 / 5745$ & $100 \%$ \\
16 & 0 & $11031 / 11031$ & $100 \%$ \\
17 & 0 & $16306 / 16306$ & $100 \%$ \\
18 & 0 & $22425 / 22425$ & $100 \%$ \\
19 & 0 & $28217 / 28217$ & $100 \%$ \\
20 & 0 & $31381 / 31381$ & $100 \%$ \\
\hline \hline
\end{tabular}

Hasil uji coba menunjukkan bahwa 20 keluaran solusi dari 20 kali uji coba sama dengan keluaran hasil data generator. Keluaran hasil data generator dipastikan benar. Hasil dari 20 kali uji coba kebenaran tertera pada Tabel 9.

\section{B. Uji Coba Kinerja}

Uji coba kinerja dilakukan dengan mengukur lama berjalannya solusi perangkat lunak dengan 20 masukan yang sama dan urutan yang sama dengan masukan yang digunakan untuk uji coba kebenaran. Hasil uji coba pada Gambar 3 menunjukkan waktu eksekusi maksimal adalah 178 detik, waktu eksekusi minimal adalah 3.482 detik, dan waktu ratarata adalah 84.2321 detik.

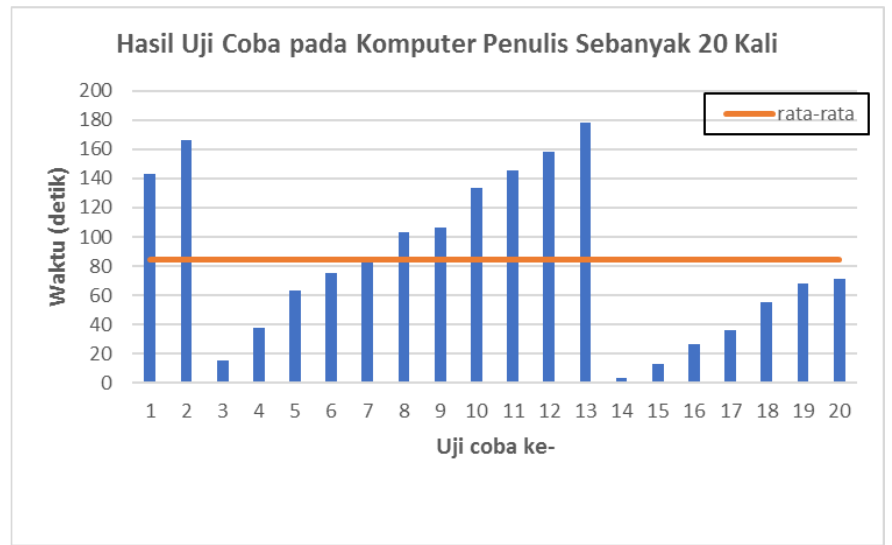

Gambar 3. Hasil uji coba kinerja sebanyak 20 kali

Uji coba kinerja juga dilakukan untuk mengukur pengaruh banyak urutan berkala awal $\mathrm{N}$ terhadap pertumbuhan waktu.

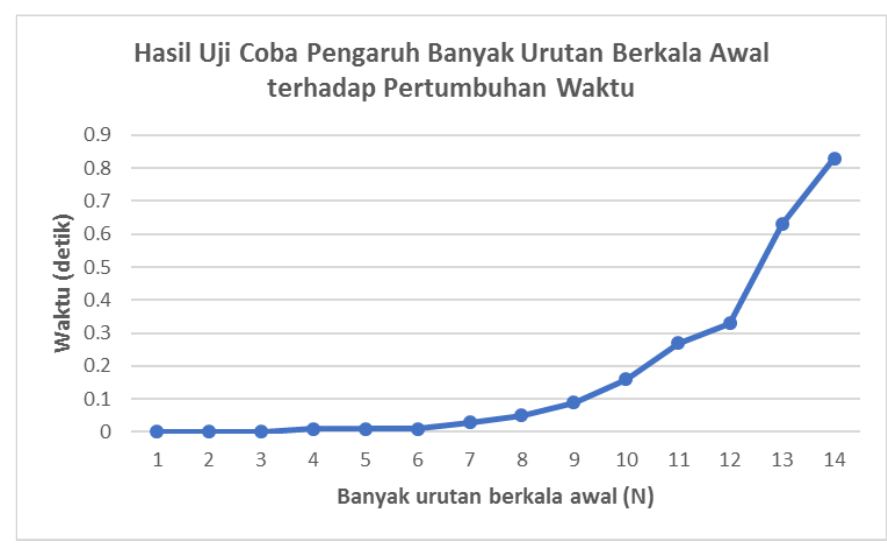

Gambar 4. Pengaruh banyak urutan berkala awal terhadap pertumbuhan waktu

Hasil uji coba pada Gambar 4 menunjukkan bahwa pertumbuhan waktu yang terjadi bersifat eksponensial.

\section{KESIMPULAN/RINGKASAN}

Dari hasil uji coba yang telah dilakukan terhadap implementasi penyelesaian permasalahan, dapat diambil kesimpulan sebagai berikut:

1. Implementasi metode eliminasi gauss menghasilkan jawaban prediksi yang tepat untuk 20 kasus acak.

2. Waktu yang dibutuhkan oleh perangkat lunak untuk melakukan penyelesaian permasalahan mengalami pertumbuhan secara eksponensial pangkat 6 terhadap pertumbuhan banyak urutan berkala awal.

3. Kompleksitas waktu yang dibutuhkan untuk seluruh proses perangkat lunak adalah $O\left(T N^{6}+T N^{2}\right)$ pada banyak sub-kasus uji $T$ dan banyak urutan berkala awal $N$.

4. Perlu adanya optimasi waktu dengan mengubah permasalahan ke dalam bentuk interpolasi trigonometri yang diselesaikan dengan metode interpolasi polinomial Lagrange dan perkalian polinomial yang diselesaikan dengan metode transformasi Fourier 
cepat.

\section{UCAPAN TERIMA KASIH}

Penulis mengucapkan terima kasih kepada Tuhan Yang Maha Esa atas segala karunia dan rahmat-Nya yang telah diberikan selama ini. Penulis juga mengucapkan terima kasih kepada orang tua yang selalu menyemangati penulis D.H. (inisial nama mahasiswa) dengan menanyakan progress penelitian setiap minggu, saudara penulis D.H. yang selalu memberikan semangat, Bapak Rully Soelaiman dan Bapak Victor Hariadi selaku dosen pembimbing penulis D.H., serta seluruh pihak yang tidak bisa penulis D.H. sebutkan satu persatu yang telah memberikan dukungan selama penelitian ini.

\section{DAFTAR PUSTAKA}

[1] SPOJ, "PERIOD4 - Periodic function, trip 3 (easy)," 2015. [Online]. Available: http://www.spoj.com/problems/PERIOD4/.

[2] NOAA, "Solar Cycle Progression," 2017. [Online]. Available: http://www.swpc.noaa.gov/products/solar-cycle-progression.

[3] P. C. v. O. dan S. A. V. A. J. Menezes, Handbook of Applied Cryptography. Boca Raton: CRC Press, 1997.

[4] H. A. dan C. Rorres, Elementary Linear Algebra Ninth Edition Applications Version. Hokoben: John Wiley \& Sons, 2003.

[5] S. C. C. dan R. P. Canale, umerical Methods for Engineers Sixth Edition. New York: McGraw-Hill Education, 2009. 